\title{
Randomized noninferiority study evaluating the efficacy of 2 commercial dry cow mastitis formulations
}

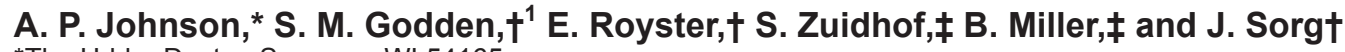 \\ *The Udder Doctor, Seymour, WI 54165 \\ †Department of Veterinary Population Medicine, University of Minnesota, Saint Paul 55108 \\ ¥Boehringer Ingelheim Vetmedica Inc., St. Joseph, MO 64506
}

\begin{abstract}
The study objective was to compare the efficacy of 2 commercial dry cow mastitis formulations containing cloxacillin benzathine or ceftiofur hydrochloride. Quarter-level outcomes included prevalence of intramammary infection (IMI) postcalving, risk for cure of preexisting infections, risk for acquiring a new IMI during the dry period, and risk for clinical mastitis between dry off and $100 \mathrm{~d}$ in milk (DIM). Cow-level outcomes included the risk for clinical mastitis and the risk for removal from the herd between dry off and 100 DIM, as well as Dairy Herd Improvement Association (DHIA) test-day milk component and production measures between calving and 100 DIM. A total of 799 cows from 4 Wisconsin dairy herds were enrolled at dry off and randomized to 1 of the 2 commercial dry cow therapy (DCT) treatments: cloxacillin benzathine (DC; $\mathrm{n}=401)$ or ceftiofur hydrochloride (SM; $\mathrm{n}=398$ ). Aseptic quarter milk samples were collected for routine bacteriological culture before DCT at dry off and again at 0 to 10 DIM. Data describing clinical mastitis cases and DHIA test-day results were retrieved from onfarm electronic records. The overall crude quarter-level prevalence of IMI at dry off was $34.7 \%$ and was not different between treatment groups. Ninety-six percent of infections at dry off were of gram-positive organisms, with coagulase-negative Staphylococcus and Aerococcus spp. isolated most frequently. Mixed logistic regression analysis showed no difference between treatments as to the risk for presence of IMI at 0 to 10 DIM (DC = $22.4 \%, \mathrm{SM}=19.9 \%$ ) or on the risk for acquiring a new IMI between dry off and 0 to 10 DIM ( $\mathrm{DC}=16.6 \%, \mathrm{SM}$ $=14.1 \%)$. Noninferiority analysis and mixed logistic regression analysis both showed no treatment difference in risk for a cure between dry off and 0 to 10 DIM $(\mathrm{DC}=84.8 \%, \mathrm{SM}=85.7 \%)$. Cox proportional hazards
\end{abstract}

Received July 31, 2015.

Accepted September 20, 2015.

${ }^{1}$ Corresponding author: godde002@umn.edu regression showed no difference between treatments in quarter-level risk for clinical mastitis $(\mathrm{DC}=1.99 \%$, $\mathrm{SM}=2.96 \%)$, cow-level risk for clinical mastitis $(\mathrm{DC}=$ $17.0 \%, \mathrm{SM}=15.3 \%$ ), or on risk for removal from the herd $(\mathrm{DC}=10.7 \%, \mathrm{SM}=10.3 \%)$ between dry off and 100 DIM. Finally, multivariable linear regression with repeated measures showed no overall no difference between treatments in DHIA test-day somatic cell count linear score $(\mathrm{DC}=2.19, \mathrm{SM}=2.22)$, butterfat test $(\mathrm{DC}$ $=3.84 \%, \mathrm{SM}=3.86 \%)$, protein test $(\mathrm{DC}=3.02 \%, \mathrm{SM}$ $=3.02 \%$ ), or 305-d mature-equivalent milk production $(\mathrm{DC}=11,817 \mathrm{~kg}, \mathrm{SM}=11,932 \mathrm{~kg})$ between calving and 100 DIM. In conclusion, DC was noninferior to SM in effecting a cure, and there was no difference in efficacy between these 2 DCT formulations as related to all other udder health or cow performance measures evaluated between dry off and 100 DIM.

Key words: dry cow mastitis, dry cow therapy, udder health, cure, intramammary infection

\section{INTRODUCTION}

Dry cow mastitis, which considers the persistence of preexisting IMI through the dry period as well as development of new IMI (NIMI) during the dry period, is a critical determinant for subclinical and clinical mastitis in the next lactation (Smith et al., 1985; Erskine, 2001; Green et al., 2002). North American studies estimate that between 13 and $35 \%$ of quarters are infected subclinically at dry off, and that between 8 and $25 \%$ of quarters develop a NIMI during the dry period (Godden et al., 2003; Cook et al., 2005; Pantoja et al., 2009; Arruda et al., 2013a). Todhunter et al. (1995) estimated that $55 \%$ of environmental infections established early in the dry period persist into the next lactation and can possibly cause clinical mastitis flare ups. Bradley and Green (2000) reported that $52 \%$ of all clinical coliform mastitis cases occurring in the first $100 \mathrm{~d}$ of lactation may originate during the previous dry period.

Blanket dry cow therapy (DCT), or the practice of infusing all quarters with a long-acting antibiotic at 
dry off, is a long-standing and widely adopted mastitis control strategy recommended by the National Mastitis Council (NMC). Blanket DCT works by curing existing subclinical infections caused by susceptible bacteria and by preventing NIMI that may be acquired during the early dry period. It is estimated that $72.3 \%$ of US dairy operations use blanket DCT, which corresponds to $81.7 \%$ of US dairy cows (USDA-NAHMS, 2008). Currently, 7 commercial DCT products have been approved by the Food and Drug Administration for use in US dairy herds (National Milk Producers Federation, 2014). Milk and meat withholding period, minimum dry period length, claimed spectrum of action, and cost for these products vary considerably.

Whereas all DCT formulations available in the United States originally underwent testing to demonstrate efficacy against a negative control as a requirement for licensure by the Food and Drug Administration, relatively few studies exist to compare efficacy among DCT products. One recent randomized clinical trial of 1,091 cows from 6 commercial dairy herds in 4 states (CA, IA, MN, and WI) compared efficacy among 3 dry cow mastitis formulations: penicillin/dihydrostreptomycin, ceftiofur hydrochloride, and cephapirin benzathine (Arruda et al. 2013a,b). The results of that study indicated no difference among the 3 DCT products studied regarding the prevalence of IMI postcalving, cure of preexisting IMI during the dry period, or development of new IMI during the dry period. Furthermore, that study reported no difference among the 3 treatments when considering quarter- and cow-level risk for a clinical mastitis event before 100 DIM, removal from the herd before 100 DIM, and SCC linear score (LS) and milk production up to 100 DIM (Arruda et al., 2013a,b). In another study, Hallberg et al. (2006) evaluated the efficacy of different doses of ceftiofur hydrochloride for the treatment of existing IMI at dry off and prevention of NIMI during the dry period using a negative control and a positive control (cephapirin benzathine). However, that study was not designed to compare efficacy between the 2 different antimicrobial formulations used (ceftiofur hydrochloride vs. cephapirin benzathine). Furthermore, Hallberg et al. (2006) only enrolled cows with an elevated SCC (>400,000 cells/ mL) and results may not be generalizable to commercial dairy herds wherein blanket DCT is usually applied to all cows. A recent study conducted in Florida compared treatment with ceftiofur hydrochloride versus cephapirin benzathine at the cow level, but the authors did not report quarter-level outcomes such as risk for NIMI or risk for cure of preexisting IMI (Pinedo et al., 2012).

Although the aforementioned efficacy study conducted by Arruda et al. $(2013 \mathrm{a}, \mathrm{b})$ provides producers with good information comparing the efficacy of the 3 available
DCT formulations containing ceftiofur hydrochloride, cephapirin benzathine, and penicillin/dihydrostreptomycin, additional comparative efficacy studies are needed to evaluate other DCT formulations available to North American dairy producers. One DCT formulation which is lacking comparative efficacy data is Dry-Clox (DC; Boehringer Ingelheim Vetmedica Inc., St Joseph, MO). Dry-Clox is composed of $500 \mathrm{mg}$ of cloxacillin benzathine and is labeled for the treatment of mastitis during the dry period caused by Streptococcus agalactiae and Staphylococcus aureus, including penicillin-resistant strains. It has a $30-d$ meat withholding time postinfusion and zero hour milk discard postcalving, following a minimum dry period length of $30 \mathrm{~d}$. Another commonly used DCT formulation is Spectramast DC (SM; Zoetis, Florham Park, NJ), which is composed of $500 \mathrm{mg}$ of ceftiofur hydrochloride and labeled for subclinical mastitis associated with Staphylococcus aureus, Streptococcus dysgalactiae, and Streptococcus uberis. This product has a meat withdrawal period of $16 \mathrm{~d}$ postinfusion and, similar to DC, has a required dry period length of $30 \mathrm{~d}$ and no milk withholding time following calving. As both the DC and SM formulations are labeled against grampositive infections, have a 30-d required dry period, and have a zero hour milk discard following calving, it would be very useful for producers to know of any differences in efficacy when considering DCT products for use on their farm.

The current study objective was to compare the efficacy of DC (cloxacillin benzathine) versus SM (ceftiofur hydrochloride) as assessed by both quarter- and cow-level measures of udder health, as well as cow performance measures during the first 100 DIM. Our hypothesis was that quarters infused with DC at the time of dry off would have a noninferior proportion of quarters cured from preexisting IMI as compared with SM. Furthermore, we hypothesized no difference would be noted between DC and SM in terms of the quarterlevel risk for presence of IMI postcalving, the risk for acquiring NIMI during the dry period, and the risk for a clinical mastitis event between dry off and 100 DIM. At the cow-level we hypothesized no effect of treatment would be observed on risk for clinical mastitis or risk for removal from the herd (death or culling) between dry off and 100 DIM, and no difference in DHIA testday milk component and production measures during the first 100 DIM.

\section{MATERIALS AND METHODS}

\section{Herd Selection}

This randomized clinical trial was conducted in a convenience sample of 4 commercial Wisconsin Holstein 
dairy farms between July 2014 and April 2015, under the University of Minnesota Institutional Animal Care and Use Committee. To be eligible to participate, herds needed to have a unique cow identification system (ear tag), be on a regular DHIA testing program ( $\geq 9$ tests per year), and have a minimum 30-d target dry period length as required by the product label for the DC and SM products. Candidate herds were prescreened using bulk tank culture to ensure they were negative for Mycoplasma spp. Briefly, for each herd, bulk tank milk samples were collected on 5 consecutive days, frozen at $-20^{\circ} \mathrm{C}$, and then later thawed and commingled before culture for Mycoplasma spp. at the participating microbiology laboratory (Waupun Veterinary Service Milk Quality Laboratory, Waupun, WI).

\section{Cow Enrollment at Dry Off}

All cow enrollment and sampling activities were completed by designated trained personnel within each herd, with training and supervision conducted by the principle investigator (A. P. Johnson). To be eligible for enrollment cows had to be in good general health, have 4 functioning quarters, have not received parenteral or intramammary treatment with an antibacterial or antiinflammatory medication during a $30-\mathrm{d}$ period immediately before dry off, show no clinical signs of mastitis on the day of dry off, and have an expected dry period length greater than $30 \mathrm{~d}$. Cows were dried off once per week in each herd. On dry off day, cows due to be dried off were brought into the parlor for their last milking and routine DCT. Animals were identified and visually inspected for clinical signs of illness, such as very low BCS $(<2.0)$ or moderate-to-severe lameness, and the udder and milk were inspected for signs of clinical mastitis. Eligible cows were identified by application of a unique colored leg band attached to the rear leg and then randomly allocated to treat all 4 quarters with 1 of the 2 treatments (DC or SM) according to a previously prepared randomized spreadsheet created in Excel (Microsoft Corporation, Redmond, WA). Randomization was blocked within farm for each day of enrollment (blocked every 6 cows).

Prior to sampling, routine udder preparation was performed by parlor staff. Whereas the type of predip used and sequence of predipping and forestripping was not identical among all herds, the general process involved predipping, forestripping, redipping, leaving the dip on for at least $45 \mathrm{~s}$ of contact time, and then wiping teat barrel and teat end dry with a clean cloth towel. Following udder preparation, the designated sampling person disinfected the teat ends using gauze squares soaked in $70 \%$ isopropyl alcohol. Three strippings of fore milk were discarded and $10-\mathrm{mL}$ duplicate quarter milk samples were aseptically collected into sterile vials identified with herd, cow number, quarter, and date. After sample collection $(\mathbf{S} 1=$ sample 1$)$, the final milking procedure took place and milk sample vials were placed into a chilled cooler on ice. Immediately following the final milking, all 4 teat ends were again scrubbed with alcohol-soaked gauze, the assigned treatment (DC or SM) was infused into each of the 4 quarters, and, finally, the internal teat sealant was infused into all quarters of all cows (Orbeseal, Zoetis, New York, NY). All cows were postdipped with a disinfectant and moved to their respective dry cow facilities, where usual farm dry cow husbandry and management practices were undertaken. Throughout the dry period, herd staff recorded any clinical mastitis events (cow identification, date, quarter) and other health events (e.g., abortion, death, culling). The S1 (enrollment) duplicate quarter milk samples were frozen at $-20^{\circ} \mathrm{C}$ within $2 \mathrm{~h}$ of collection and shipped weekly to the microbiology laboratory for culture.

\section{Postcalving Sampling and Follow-Up}

Following calving, the designated personnel within each herd were to collect aseptic duplicate quarter milk samples $(\mathbf{S 2}=$ sample 2$)$ once between 0 and 10 DIM using the same sample collection procedure as was previously described for the S1 samples collected at dry off. All clinical mastitis events occurring in the first 100 DIM were recorded by farm staff using an onfarm electronic record-keeping system (DairyComp305, Valley Agricultural Software, Tulare, CA), and farm personnel were asked to collect and freeze an aseptic milk sample from the affected quarter at time of detection of a clinical case. Clinical mastitis was defined as visibly abnormal milk accompanied or not by changes in the quarter. The S2 samples and clinical mastitis samples were frozen at $-20^{\circ} \mathrm{C}$ on the farm and shipped weekly to the microbiology laboratory for culture. On-farm DairyComp305 software was used to capture health events (e.g., calving, death, culling, clinical mastitis) and DHIA test-day records [e.g., SCC LS, 305-d mature-equivalent milk yield $(305 \mathrm{ME} ; \mathrm{kg})$, butterfat percent, protein percent] for each test day for all study cows for the period between enrollment and 100 DIM.

\section{Milk Culture Methods}

All frozen S1, S2, and clinical mastitis samples from farms were placed on ice and transported to the local participating microbiology laboratory on a weekly basis (Waupun Veterinary Service Milk Quality Laboratory). Milk culture procedures followed published procedures recognized by the NMC for bovine mastitis (NMC, 
1999). Only one of each pair of duplicate quarter samples collected at dry off (S1) and calving (S2) was routinely selected for microbial culture. The second paired sample was kept frozen in reserve and only cultured in cases where the first sample was contaminated. Samples to be cultured were thawed to room temperature and $0.01 \mathrm{~mL}$ of milk was plated onto blood and MacConkey agar (BD, Franklin Lakes, NJ) using calibrated loops. Inoculated plates were incubated at $37^{\circ} \mathrm{C}$ for $48 \mathrm{~h}$ and then observed for bacterial growth. For plates with bacterial growth, the number of colonies was recorded for each species isolated and colonies were reisolated on blood agar for further characterization. Colony morphology, hemolysis pattern, and Gram staining results were described.

Further characterization of gram-positive organisms involved the catalase test reaction to differentiate Staphylococcus and Streptococcus species and then coagulase testing. Organisms that were catalase positive and coagulase negative were reported as CNS, whereas catalase- and coagulase-positive organisms were reported as Staphylococcus aureus. Catalase-negative organisms had their identity confirmed by the API Streptococcus identification system (bioMerieux-Vitek Inc., Hazelwood, MO). Pathogens reported as other Streptococcus spp. corresponded to subspecies of Streptococcus that are less commonly reported in literature or to pathogens that could not be identified by the API Streptococcus system. Gram-positive organisms that were in very low prevalence and could not be identified with biochemical tests were reported as other gram positive. Further characterization of gram-negative organisms involved testing with the API20E system (bioMerieux-Vitek Inc.). Organisms that could not be identified by the API system were reported as other gram negative. Finally, nonbacterial pathogens such as yeast were reported as other. If 3 or more pathogens were present in a single sample, it was considered contamination and the duplicate sample was cultured. If the duplicate sample was also contaminated then the quarter sample was reported as contaminated. Blinding of the sample collectors or producer on farm at the time of enrollment was not possible; however, laboratory personnel were blinded to treatment.

\section{Definitions}

Presence of IMI. An IMI was defined as one or more colonies isolated from a 0.01-mL milk sample for all pathogens except for CNS and Bacillus spp. For CNS, 2 or more colonies isolated from a $0.01-\mathrm{mL}$ milk sample were needed to establish presence of an IMI (Dohoo et al., 2011a). For Bacillus spp, an IMI was defined as 5 or more colonies isolated from a $0.01-\mathrm{mL}$ milk sample. As no peer-reviewed studies exist determining a cut-off point for the latter organism, the definition for IMI for Bacillus spp. was established during an informal discussion among mastitis experts conducted during the Mastitis Research Workers' Conference (Nov 1, 2011, Chicago, IL). A single IMI was defined as the presence of only one type of pathogen in the sample, whereas mixed infections corresponded to the presence of 2 different bacterial species.

Bacteriological Cure. A cure was defined as the failure to culture 1 or 2 of the pathogens originally present at the dry off sample in the postcalving sample (S2). For a mixed infection present at S1, both organisms had to be absent in the S2 sample to classify the quarter as cured. Quarters that had contaminated or missing samples were excluded from this analysis.

NIMI. A NIMI was defined as quarters from which no pathogens were recovered at dry off (S1) but growth was later detected in the postcalving sample (S2) or a different (new) pathogen was recovered at $\mathrm{S} 2$ as compared with S1. Quarters that had contaminated or missing samples were excluded from this analysis. It was possible for the same quarter to experience both a cure and a NIMI.

\section{Data Analysis}

Sample Size Calculations. For the a priori sample size calculation for the noninferiority portion of our study, the primary outcome considered was risk for a cure between dry off and 0 to 10 DIM. The minimum difference in cure rate to declare noninferiority of DC, as compared with SM, was prestated at $10 \%$. To demonstrate noninferiority, a total of 339 cows (1356 quarters) per group were estimated to be required assuming $\alpha=0.025$ and $\beta=0.2$, with $10 \%$ inflation to adjust for within-herd clustering of cows, and assuming that $30 \%$ of the quarters would be infected at dry off and therefore at risk for a cure (non-inferiority tests for two proportions, PASS 2008; NCSS, Kaysville, UT). However, this number was inflated to 390 cows $(1,560$ quarters) per group to account for an anticipated $15 \%$ loss to follow-up due to culling, missing samples, or contaminated samples.

Description of Cow and Quarter Characteristics at Enrollment. All statistical analyses were conducted using SAS version 9.3 (SAS Institute Inc., Cary, NC). Descriptive statistics were generated for exploratory data analysis and basic diagnostic techniques were used to evaluate normality and presence of outliers. Characteristics of cows and quarters assigned to the 2 treatment groups, including previous lactation length (days), parity, dry period length (days), previous lactation LS at last DHIA test before dry off (DryLS), 
and previous lactation total milk, fat, and protein production $(\mathrm{kg})$ were compared at baseline (dry off) using ANOVA.

Effect of Treatment on Quarter-Level Measures of Udder Health. Univariable logistic regression (GLIMMIX procedure) was first used to investigate the relationship between treatment (DC or SM) and each of the following quarter-level binary outcomes: (1) risk for presence of IMI at S1, (2) risk for presence of IMI at S2, (3) risk for cure between dry off and 0 to 10 DIM, and (4) risk for NIMI between dry off and 0 to 10 DIM. Herd was forced into all models as a fixed effect to account for the clustering of cows within herd. A term describing quarter within cow was included in all quarter-level models as a random statement to adjust for the clustering of quarters within cow. Univariable logistic regression was also used to investigate if other cow characteristics were associated with each of the aforementioned 4 outcome variables, including parity, DryLS, previous lactation total milk, fat or protein production $(\mathrm{kg})$, previous lactation length (days), and dry period length (days), all offered as continuous variables.

Main effects significant at $P<0.20$ in the previously described univariable models were carried forward to offer to a multivariable model investigating the effect of treatment (DC vs. SM; forced) on the 4 outcome variables of interest. A backward stepwise approach was then used to remove nonsignificant variables one at a time, starting with the least significant variable first (largest $P$-value), until only significant variables remained $(P<0.05)$. Potential confounders were investigated; to be a potential confounder, a variable had to be significantly associated with both the explanatory variable (treatment group) and the outcome variable of interest for a given model. A variable was identified as a confounder and retained in the model if its exclusion from the model resulted in $>15 \%$ change in the estimate of the effect of treatment on the outcome variable of interest. All models were investigated for the presence of an interaction between treatment and all other significant variables, but no interactions were found to exist. Models were compared during the model building process using the -2 log-likelihood statistic and model fit was evaluated by use of the Hosmer and Lemeshow goodness-of-fit test. Noninferiority analysis of the effect of treatment with DC on risk for a bacteriological cure was completed by calculating the cure rate difference (95\% CI) for DC as compared with SM, and then comparing the lower bound of the CI for the rate difference for DC against the critical value, $\Delta(0.10$; Piaggio et al., 2006).

Effect of Treatment on Risk for Clinical Mastitis and Risk for Removal from the Herd by 100 DIM. All quarters and cows enrolled were considered at risk for a clinical mastitis event and for removal from the herd between dry off and 100 DIM. After describing the crude proportions affected, Cox proportional hazards regression (PHREG procedure) was used to describe the effect of treatment on risk for each of the following time-to-event outcomes occurring between enrollment and 100 DIM: (1) quarter-level risk for a clinical mastitis event, (2) cow-level risk for a clinical mastitis event, and (3) cow-level risk for removal from the herd (death or culling). For each of these 3 models, the failure date was defined as the date when the event of interest (i.e., clinical mastitis or removal) was first reported between enrollment and 100 DIM. For the clinical mastitis time-to-event models, quarters or cows not reported to experience clinical mastitis by 100 DIM were classified as right censored at the cow's culling or death date (if removed before 100 DIM) or were right-censored at 100 DIM. For the herd removal time-to-event model, cows not reported to experience a removal event by 100 DIM were right-censored at 100 DIM. Apart from the terms describing treatment and herd, which were both forced, other explanatory variables investigated for inclusion in these models using a backward elimination process (as previously described) included parity, DryLS, previous lactation total milk, fat or protein production $(\mathrm{kg})$, previous lactation length (days), and dry period length (days). An interaction effect between treatment and all other significant covariates was investigated but was found not to be present. Because the Cox model assumes a proportional hazard constant over time, this assumption was tested by creating a time dependent variable [treatment $\times \log ($ time $)$ ] inside the PHREG procedure and testing this term for proportionality using the proportionality_test statement. The results of the proportionality test were not significant for the 3 time-to-event models, indicating the models did not violate the assumption that proportional hazards were constant over time.

Effect of Treatment on DHIA Test-Day Measures of LS, Components, and Milk Production in Early Lactation. Mixed linear regression (MIXED procedure) was used to investigate the effect of treatment on each of the following 4 DHIA test-day outcome measures for all DHIA test days occurring between calving and 100 DIM: (1) SCC LS, (2) butterfat test (\%), (3) protein test (\%), and (4) 305ME milk yield $(\mathrm{kg})$. For all 4 models, treatment and herd were forced as a fixed effect, with repeated measures on each DHIA test number $(1,2$, or 3$)$. Other explanatory variables investigated for inclusion in these models included DIM on test day, parity, previous lactation dryLS, previous lactation total milk, fat and protein production $(\mathrm{kg})$, and dry period length (days). Univariate analysis was initially conducted to evaluate the relationship between 
each of the aforementioned explanatory variables and the dependent variable of interest. Variables significant at $P<0.2$ in the univariate analysis were carried forward to offer into the full model. Nonsignificant variables were then removed from the model using a backward stepwise approach with final significance declared at $P<0.05$. A variable was considered a confounder and retained in the final model if its inclusion in the model changed the estimate of the effect of the DCT treatment group on the dependent variable by $15 \%$ or greater. First-order interactions between treatment group and all other significant main effects terms were tested. Models were compared during the model building process using the -2 Log-likelihood statistic, and model fit was evaluated by plotting marginal and conditional residuals.

\section{RESULTS}

\section{Herd Characteristics}

This convenience sample of 4 Holstein herds averaged 1,663 lactating cows, with an average bulk tank SCC of 172,500 cells/mL and tank average milk production of $40.3 \mathrm{~kg} /$ cow per day. Other herd production information, bedding, and housing characteristics are described in Table 1. All herds routinely used blanket dry cow therapy and an internal teat sealant at dry off (Orbeseal, Zoetis), as well as a coliform mastitis vaccine program (Enviracor J-5, Zoetis; 4 shots, delivered at dry off, 3-4 wk precalving, $21 \mathrm{~d}$ postcalving, and $90 \mathrm{~d}$ postcalving).

\section{Cow Characteristics at Enrollment}

A total of 799 cows (3,196 quarters) were enrolled between June 5 and October 6, 2014, with 401 cows (1,604 quarters) and 398 cows (1,592 quarters) enrolled into the DC and SM groups, respectively. Cow numbers were relatively equally distributed among the 4 participating herds, with 177, 207, 202, and 213 cows enrolled from herds 1, 2, 3, and 4, respectively. A similar balance of cows were assigned to the DC and SM treatment groups within each herd: herd $1: \mathrm{DC}=87, \mathrm{SM}=90$; herd $2: \mathrm{DC}=108, \mathrm{SM}=99$; herd $3: \mathrm{DC}=100, \mathrm{SM}=$ 102 ; and herd $4: \mathrm{DC}=106, \mathrm{SM}=107$. Analysis of variance showed that enrollment characteristics, including parity, Dry LS, and previous lactation total milk, fat, and protein yield, were not different for cows between the 2 treatment groups. Also dry period length was not different between groups $(P>0.10$ for all comparisons; Table 2). Overall, the mean $( \pm \mathrm{SD})$ parity, DryLS, and previous lactation total milk, fat, and protein yield for all cows was $2.7 \pm 1.0,3.1 \pm 1.9,13,432 \mathrm{~kg} \pm 3,763$, $490 \pm 109 \mathrm{~kg}$, and $409 \pm 109 \mathrm{~kg}$, respectively. The mean dry period length for all cows was $58.0 \pm 10.8 \mathrm{~d}$.

\section{IMI Status at Dry Off}

Of the 3,196 quarters originally enrolled, 208 quarters (6.5\%) were omitted due to contamination of the S1 sample collected at dry off, leaving 2,988 quarters for analysis of infection status at dry off. The rate of contaminated samples at dry off was not different between treatment groups $(\mathrm{DC}=6.6 \%$, or 106 of 1,$608 ; \mathrm{SM}$ $=6.4 \%$, or 102 of 1,588$)$. When examining the crude prevalence of IMI at dry off, the overall prevalence of IMI (all quarters) and the prevalence of IMI by herd was $34.7 \%$ (overall) and $41.3,19.9,51.4$, and $30.5 \%$ for herds 1, 2, 3, and 4, respectively (Table 3). The overall proportion of infections caused by gram-positive organisms was $95.7 \%$, but ranged between 89.1 (herd 1) and $99.6 \%$ (herd 4). Conversely, the overall proportion of infections at dry off caused by gram-negative organisms was $4.3 \%$, ranging between 0.4 (herd 4) and $10.9 \%$ (herd 1; Table 3). Whereas CNS was the predominant organism recovered for all herds, the relative frequency of this and other types of gram-positive and gram-negative infections varied by herd (Table 3).

The crude proportion of quarters with IMI present at dry off was similar between the DC group (35.4\%,

Table 1. Herd characteristics

\begin{tabular}{|c|c|c|c|c|c|}
\hline Item & Herd 1 & Herd 2 & Herd 3 & Herd 4 & Average \\
\hline Size (no. of lactating cows) & 1,550 & 1,500 & 1,100 & 2,500 & 1,663 \\
\hline Milk production (kg/cow per day) & 32.7 & 44.5 & 40.9 & 43.2 & 40.3 \\
\hline Bulk tank $\mathrm{SCC}^{1}$ (cells $\left./ \mathrm{mL}\right)$ & 164,000 & 122,000 & 194,000 & 210,000 & 172,500 \\
\hline Bulk tank protein (\%) & 3.39 & 3.13 & 2.97 & 3.19 & 3.17 \\
\hline Bulk tank fat (\%) & 4.0 & 3.56 & 3.65 & 3.96 & 3.79 \\
\hline Housing during far-off dry period ${ }^{2}$ & Freestalls & Freestalls & Freestalls & Freestalls & - \\
\hline Bedding during far-off dry period ${ }^{2}$ & Biosolids & Recycled sand & New sand & Recycled sand & - \\
\hline Housing during close-up dry period ${ }^{3}$ & Bedded pack & Freestalls & Freestalls & Freestalls & - \\
\hline Bedding during close-up dry period ${ }^{3}$ & Straw & Recycled sand & Biosolids & Recycled sand & - \\
\hline
\end{tabular}

${ }^{1}$ Bulk tank milk SCC average.

${ }^{2}$ Far-off dry period is from dry off to approximately $30 \mathrm{~d}$ precalving.

${ }^{3}$ Close-up dry period is approximately $30 \mathrm{~d}$ precalving to calving. 
Table 2. Enrollment characteristics of cows infused with Dry-Clox ${ }^{1}$ or Spectramast DC ${ }^{2}$ at dry off ${ }^{3}$

\begin{tabular}{lcc}
\hline & \multicolumn{2}{c}{ Treatment group } \\
\cline { 2 - 3 } Parameter & Dry-Clox & Spectramast DC \\
\hline Number of cows & 401 & 398 \\
Parity & $2.65 \pm 0.95$ & $2.75 \pm 0.97$ \\
Previous lactation length (d) & $340 \pm 63.8$ & $344 \pm 64.4$ \\
SCC linear score at dry off & $3.07 \pm 1.89$ & $3.21 \pm 1.96$ \\
Previous lactation fat yield (kg) & $484 \pm 131$ & $493 \pm 144$ \\
Previous lactation protein yield (kg) & $405 \pm 105$ & $410 \pm 113$ \\
Previous lactation milk yield $(\mathrm{kg})$ & $13,406 \pm 3,716$ & $13,403 \pm 3,798$ \\
Dry period length (d) & $58.4 \pm 9.8$ & $57.6 \pm 11.7$ \\
\hline
\end{tabular}

${ }^{1}$ Dry-Clox (500 mg cloxacillin benzathine; Boehringer Ingelheim Vetmedica, Inc., St Joseph, MO).

${ }^{2}$ Spectramast DC (500 mg ceftiofur hydrochloride; Zoetis, Florham Park, NJ).

${ }^{3}$ Table reports mean \pm SD; ANOVA showed no treatment group difference for any parameter $(P>0.10$ for all comparisons).

or 532 of 1,502) and the SM group (34.1\%, or 506 of $1,486)$. The final mixed logistic model showed no association between treatment and the risk for presence of IMI at dry off $[\mathrm{DC}=35.2 \%$; $\mathrm{SM}=33.8 \%$; odds ratio $_{\mathrm{DC}}=1.06(0.91,1.25), P=0.45$; Table 4]. A positive association was observed between DryLS and risk for IMI at dry off. A negative association was noted between parity and risk for IMI at dry off. There were significant differences among the 4 herds in risk for presence of IMI at dry off (Table 4). Gram-positive and -negative species represented 95.7 and $4.3 \%$ of all isolates present at dry off, respectively (Table 5). The most frequent gram-positive isolates were CNS (69.5\%), Aerococcus spp. (9.4\%), and Bacillus spp. (7.0\%); the most frequent gram-negative isolate was Escherichia $\operatorname{coli}(1.4 \%)$.

\section{Effect of Treatment on Risk for Presence of Infection Between 0 and 10 DIM}

A total of 2,551 quarters were used for evaluation of the risk for presence of IMI after calving (0 to 10 DIM). From the 3,196 quarters originally enrolled (DC $=1,608 ; \mathrm{SM}=1,588)$ a total of 645 quarters $(20.2 \%)$

Table 3. Crude prevalence and frequency of bacterial species for quarters with infection present at dry off, by herd

\begin{tabular}{|c|c|c|c|c|c|}
\hline Item & \multicolumn{5}{|c|}{ IMI present at dry off, no. (\%) } \\
\hline Total number of quarters sampled ${ }^{1}$ & 676 & 821 & 677 & 814 & 2,988 \\
\hline Quarters with no bacterial growth & $397(58.7)$ & $658(80.1)$ & $329(48.6)$ & $566(69.5)$ & $1,950(65.3)$ \\
\hline \multicolumn{6}{|l|}{ Gram positive } \\
\hline Aerococcus spp. & $34(11.2)$ & $51(30.0)$ & $5(1.3)$ & $15(5.7)$ & $105(9.4)$ \\
\hline Corynebacterium spp. & $1(0.3)$ & $0(0)$ & $0(0)$ & $0(0)$ & $1(0.1)$ \\
\hline Enterococcus spp. & $2(0.7)$ & $26(15.3)$ & $6(1.6)$ & $20(7.6)$ & $54(4.8)$ \\
\hline Streptococcus dysgalactiae & $0(0)$ & $0(0)$ & $1(0.3)$ & $1(0.4)$ & $2(0.2)$ \\
\hline Streptococcus uberis & $0(0)$ & $0(0)$ & $5(1.3)$ & $0(0)$ & $5(0.5)$ \\
\hline Streptococcus agalactiae & $1(0.3)$ & $0(0)$ & $0(0)$ & $0(0)$ & $1(0.1)$ \\
\hline Staphylococcus aureus & $0(0)$ & $0(0)$ & $3(0.8)$ & $1(0.4)$ & $4(0.4)$ \\
\hline Other gram positive & $7(2.3)$ & $21(12.4)$ & $2(0.5)$ & $12(4.6)$ & $42(3.8)$ \\
\hline \multicolumn{6}{|l|}{ Gram negative } \\
\hline Proteus spp. & $1(0.3)$ & $0(0)$ & $0(0)$ & $0(0)$ & $1(0.1)$ \\
\hline Pseudomonas spp. & $1(0.3)$ & $0(0)$ & $0(0)$ & $0(0)$ & $1(0.1)$ \\
\hline Serratia spp. & $3(1.0)$ & $0(0)$ & $1(0.3)$ & $1(0.4)$ & $5(0.5)$ \\
\hline Other gram negative & $6(2.0)$ & $2(1.2)$ & $3(0.8)$ & $0(0)$ & $11(1.0)$ \\
\hline Total gram negative & $33(10.9)$ & $6(3.5)$ & $8(2.1)$ & $1(0.4)$ & $48(4.3)$ \\
\hline Total isolates & $304(100)$ & $170(100)$ & $378(100)$ & $263(100)$ & $1,115(100)$ \\
\hline
\end{tabular}

\footnotetext{
${ }^{1}$ Excludes contaminated samples.
} 
Table 4. Final mixed models describing factors associated with risk for IMI at dry off and after calving, for cows infused with Dry-Clox ${ }^{1}$ or Spectramast $\mathrm{DC}^{2}$ at dry off ${ }^{3}$

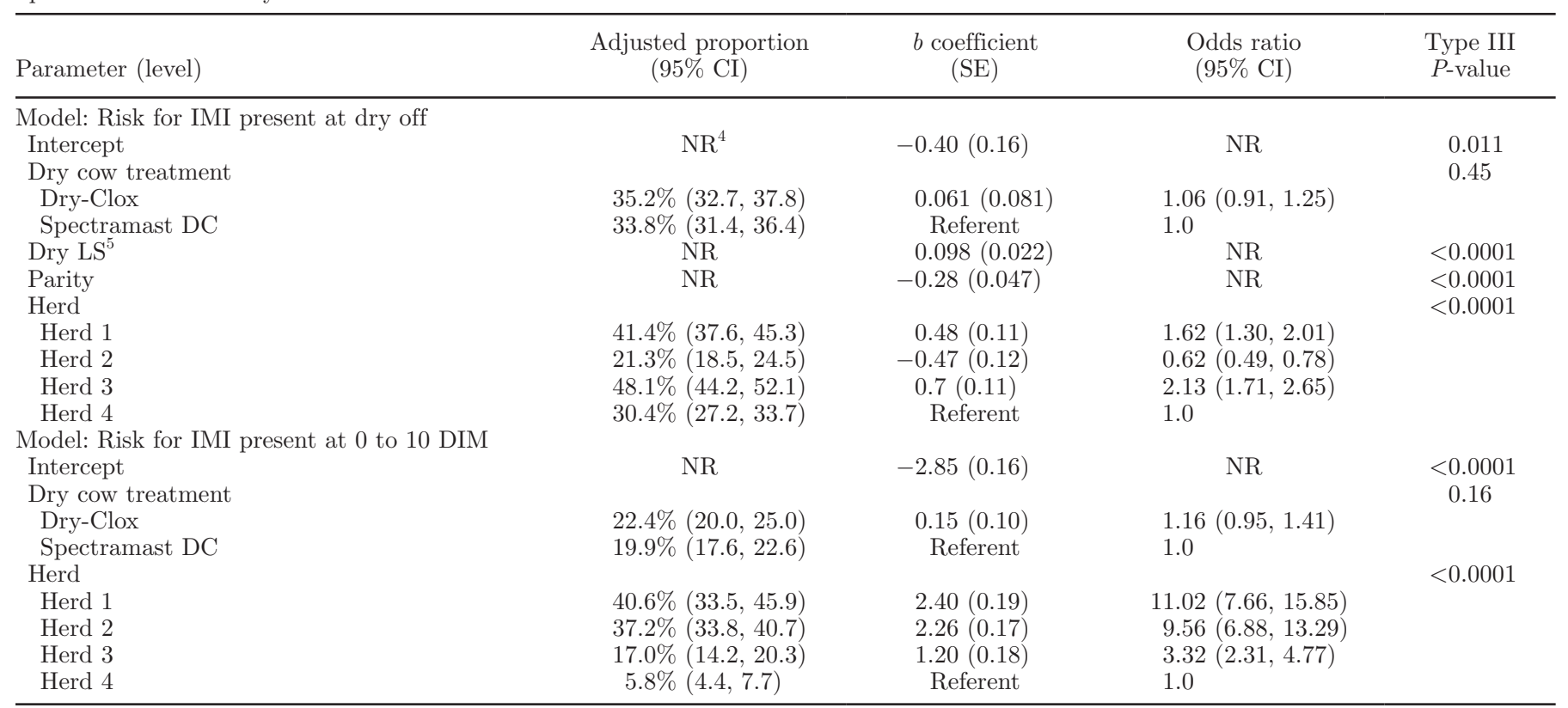

${ }^{1}$ Dry-Clox (500 mg cloxacillin benzathine; Boehringer Ingelheim Vetmedica Inc., St Joseph, MO).

${ }^{2}$ Spectramast DC (500 mg ceftiofur hydrochloride; Zoetis, Florham Park, NJ).

${ }^{3}$ Models adjusted for clustering of quarter-within-cow as a random effect.

${ }^{4} \mathrm{NR}=$ not reported.

${ }^{5}$ Somatic cell count linear score at last DHIA test before dry off.

Table 5. Crude prevalence and frequency of bacterial species for quarters with infection present at dry off or at 0-10 DIM

\begin{tabular}{|c|c|c|c|c|c|c|}
\hline Item & \multicolumn{3}{|c|}{ IMI present at dry off, no. (\%) } & \multicolumn{3}{|c|}{ IMI present at 0-10 DIM, no. (\%) } \\
\hline Total number of quarters & 1,502 & 1,486 & 2,988 & 1,307 & 1,244 & 2,551 \\
\hline Quarters with no growth & $970(64.6)$ & $980(66.0)$ & $1,950(65.3)$ & $988(75.6)$ & $976(78.5)$ & $1,964(77.0)$ \\
\hline \multicolumn{7}{|l|}{ Gram positive } \\
\hline Aerococcus spp. & $50(8.7)$ & $55(10.2)$ & $105(9.4)$ & $120(35.2)$ & $96(33.0)$ & $216(34.2)$ \\
\hline Corynebacterium spp. & $1(0.2)$ & $0(0)$ & $1(0.1)$ & $0(0)$ & $0(0)$ & $0(0)$ \\
\hline Enterococcus spp. & $38(6.6)$ & $16(3.0)$ & $54(4.8)$ & $33(9.7)$ & $23(7.9)$ & $56(8.9)$ \\
\hline Streptococcus dysgalactiae & $2(0.4)$ & $0(0)$ & $2(0.2)$ & $0(0)$ & $0(0)$ & $0(0)$ \\
\hline Streptococcus uberis & $1(0.2)$ & $4(0.7)$ & $5(0.5)$ & $0(0)$ & $0(0)$ & $0(0)$ \\
\hline Streptococcus agalactiae & $1(0.2)$ & $0(0)$ & $1(0.1)$ & $0(0)$ & $0(0)$ & $0(0)$ \\
\hline Staphylococcus aureus & $3(0.5)$ & $1(0.2)$ & $4(0.4)$ & $3(0.9)$ & $0(0)$ & $3(0.5)$ \\
\hline Other gram positive & $25(4.3)$ & $17(3.2)$ & $42(3.8)$ & $8(2.4)$ & $6(2.1)$ & $14(2.2)$ \\
\hline Proteus spp. & $0(0)$ & $1(0.2)$ & $1(0.1)$ & $0(0)$ & $0(0)$ & $0(0)$ \\
\hline Pseudomonas spp. & $0(0)$ & $1(0.2)$ & $1(0.1)$ & $0(0)$ & $0(0)$ & $0(0)$ \\
\hline Serratia spp. & $3(0.5)$ & $2(0.4)$ & $5(0.5)$ & $1(0.30$ & $3(1.0)$ & $4(0.6)$ \\
\hline Other gram negative & $4(0.7)$ & $7(1.3)$ & $11(1.0)$ & $9(2.6)$ & $7(2.4)$ & $16(2.5)$ \\
\hline Total gram negative & $18(3.1)$ & $30(5.6)$ & $48(4.3)$ & $31(9.1)$ & $24(8.2)$ & $55(8.7)$ \\
\hline Total isolates & $578(100)$ & $537(100)$ & $1,115(100)$ & $341(100)$ & $291(100)$ & $632(100)$ \\
\hline
\end{tabular}

${ }^{1}$ Dry-Clox (500 mg cloxacillin benzathine; Boehringer Ingelheim Vetmedica Inc., St Joseph, MO).

${ }^{2}$ Spectramast DC (500 mg ceftiofur hydrochloride; Zoetis, Florham Park, NJ). 
were omitted for the following reasons: 28 quarters were for cows that either died or were culled during the dry period ( $\mathrm{DC}=20, \mathrm{SM}=8), 28$ quarters were from cows that calved prematurely before meeting the 30-d dry period required to be on label for the 2 treatment products $(\mathrm{DC}=8, \mathrm{SM}=20), 205$ quarters were omitted because a postcalving sample was not collected by herd staff $(\mathrm{DC}=77, \mathrm{SM}=128), 288$ quarters were omitted because a postcalving milk sample was collected later than 10 DIM $(\mathrm{DC}=136, \mathrm{SM}=152)$, and 96 quarters were omitted because the postcalving sample was contaminated $(\mathrm{DC}=60, \mathrm{SM}=36)$. Of all 645 quarters omitted from this analysis, the proportion omitted was similar between the DC group (18.7\%, or 301 of 1,608$)$ and the SM group $(21.7 \%$, or 344 of 1,588$)$.

The crude proportion of quarters with IMI present at 0 to 10 DIM was similar between the DC group ( $24.3 \%$, or 318 of 1,307$)$ and the SM group $(21.5 \%$, or 268 of 1,244). The final mixed logistic model showed no effect of treatment on the risk for presence of IMI at 0 to 10 DIM in the DC group (22.4\%) versus the SM group $\left[19.9 \%\right.$; odds ratio $_{\mathrm{DC}}=1.16(0.95,1.41), P=$ 0.16; Table 4]. Significant differences were noted among the 4 herds in risk for presence of IMI at 0 to 10 DIM (Table 4). Gram-positive and -negative species represented 91.3 and $8.7 \%$, of all isolates in recovered from S2 samples, respectively (Table 5). The most frequent gram-positive isolates were CNS $(41.8 \%)$, Aerococcus spp. (34.2\%), and Enterococcus spp. (8.9\%); the most frequent gram-negative isolates were Escherichia coli $(3.5 \%)$ and Klebsiella spp. (2.1\%; Table 5).

\section{Effect of Treatment on Risk for Developing a New Infection Between Dry Off and 0 to 10 DIM}

From the 2,988 quarters with uncontaminated S1 samples at enrollment $(\mathrm{DC}=1,502 ; \mathrm{SM}=1,486) 605$ quarters $(20.2 \%)$ were omitted from final analysis of risk for new IMI for the following reasons: 23 quarters were from cows that either died or were culled during the dry period $(\mathrm{DC}=15, \mathrm{SM}=8), 20$ quarters were from cows that calved prematurely before meeting the $30-\mathrm{d}$ dry period required on label for the 2 treatment products $(\mathrm{DC}=4, \mathrm{SM}=16), 193$ quarters were omitted because a postcalving (S2) sample was not collected by herd staff $(\mathrm{DC}=75, \mathrm{SM}=118), 280$ quarters were omitted because the S2 milk sample was collected later than 10 DIM $(\mathrm{DC}=131, \mathrm{SM}=149)$, and 89 quarters were omitted because the $\mathrm{S} 2$ sample was contaminated $(\mathrm{DC}=53, \mathrm{SM}=36)$. Of all 605 quarters omitted from this analysis, the proportion omitted was similar between the DC group $(18.5 \%$, or 278 of 1,502$)$ and the SM group $(22.0 \%$, or 327 of 1,486$)$. In the end, 2,383 quarters $(\mathrm{DC}=1,224, \mathrm{SM}=1,159)$ were used for evaluation of effect of treatment on the risk for developing a new IMI between dry off and 0 to 10 DIM.

The crude proportion of quarters with a new IMI acquired between dry off and 0 to 10 DIM was similar between the DC group $(19.9 \%$, or 244 of 1,224$)$ and the SM group $(17.1 \%$, or 198 of 1,159). The final mixed logistic regression model showed no difference between treatments in risk for acquiring a new IMI in the DC group $(16.6 \%)$ versus the SM group [14.1\%; odds ratio $_{\text {DC }}=1.21(0.96,1.51), P=0.10$; Table 6]. Significant differences were observed among the 4 herds in risk for acquiring a new IMI between dry off and 0 to 10 DIM. A total of 89.3 and $10.7 \%$ of all new IMI were caused by gram-positive and -negative organisms, respectively. The most frequent gram-positive isolates causing NIMI were Aerococcus spp. (40.6\%), CNS (32.1\%), and Enterococcus spp. (9.9\%); the most frequent gram-negative isolates causing NIMI were Escherichia coli $(4.2 \%)$ and Klebsiella spp. (2.7\%; Table 7).

\section{Effect of Treatment on Risk for a Cure Between Dry Off and 0 to 10 DIM}

This analysis began by considering the 2,383 quarters $(\mathrm{DC}=1,224, \mathrm{SM}=1,159)$ that were used in the previously described analysis of risk for a new IMI. However, the quarter also had to have IMI present at dry off, therefore putting it at risk for a cure. After excluding 1,609 noninfected quarters at dry off $(\mathrm{DC}=819$, $\mathrm{SM}=790), 774$ quarters $(\mathrm{DC}=405, \mathrm{SM}=369)$ were included in the final analysis of effect treatment on risk for cure. The crude proportion of quarters experiencing a cure between dry off and 0 to 10 DIM was similar between the DC group (84.9\%, or 344 of 405$)$ and the SM group (85.4\%, or 315 of 369 ). The final mixed logistic regression model showed no difference in the risk for experiencing a cure in the DC group $(84.8 \%)$ versus the SM group $[85.7 \%$; odds ratio DC $=0.93(0.58,1.51), P=$ 0.75: Table 6]. Significant differences were noted among the 4 herds in risk for experiencing a cure between dry off and 0 to 10 DIM (Table 5). A total of 95.3 and $4.7 \%$ of all cures were of prior gram-positive and -negative infections, respectively (Table 7).

As the trial did not show a significant difference between DC and SM, the goal was then to identify whether the conclusion of no difference may result in a noninferiority claim. The claim of noninferiority was based on the left-hand side of the $95 \%$ confidence interval of the rate difference being smaller than the predefined noninferiority limit of $\Delta$, defined a priori as $10 \%$ (or 0.10 ). The cure rate estimates $(95 \% \mathrm{CI}$ ) for DC $[0.8480(0.7995,0.8865)]$ and SM $[0.8567(0.8069$, $0.8954)$ groups were used to calculate the cure rate difference $(95 \%$ CI $)$ for DC as being $-0.0087(-0.0708$, 
Table 6. Final mixed models describing effect of treatment on risk for acquiring a new infection and risk for experiencing a cure between dry off and 0 to 10 DIM, for cows infused with Dry-Clox ${ }^{1}$ or Spectramast-DC ${ }^{2}$ at dry off ${ }^{3}$

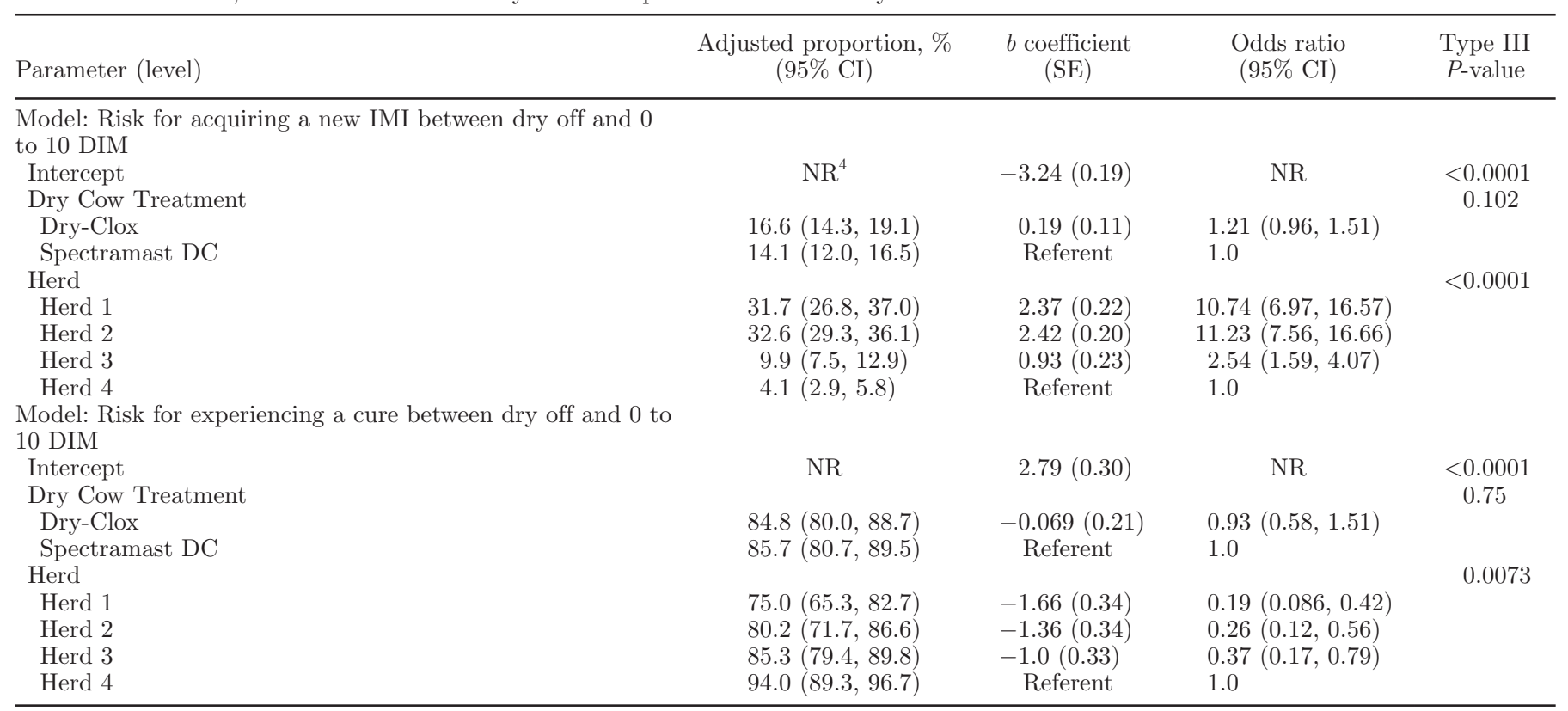

${ }^{1}$ Dry-Clox (500 mg cloxacillin benzathine; Boehringer Ingelheim Vetmedica Inc., St Joseph, MO).

${ }^{2}$ Spectramast DC (500 mg ceftiofur hydrochloride; Zoetis, Florham Park, NJ).

${ }^{3}$ Models adjusted for clustering of quarter-within-cow as a random effect.

${ }^{4} \mathrm{NR}=$ not reported.

Table 7. Crude proportion and frequency of bacterial species for new infections and cures between dry off and at 0-10 DIM

\begin{tabular}{|c|c|c|c|c|c|c|}
\hline Item & \multicolumn{3}{|c|}{ New IMI } & \multicolumn{3}{|c|}{ Cures } \\
\hline Total number of quarters at risk for the event & 1,244 & 1,159 & 2,383 & 405 & 369 & 774 \\
\hline Aerococcus spp. & $108(41.7)$ & $85(39.2)$ & $193(40.6)$ & $29(7.8)$ & $35(10.5)$ & $64(9.0)$ \\
\hline Bacillus spp. & $11(4.3)$ & $6(2.8)$ & $17(3.6)$ & $30(8.0)$ & $23(6.9)$ & $53(7.5)$ \\
\hline Enterococcus spp. & $26(10.0)$ & $21(9.7)$ & $47(9.9)$ & $30(8.0)$ & $13(3.9)$ & $43(6.1)$ \\
\hline Streptococcus dysgalactiae & $0(0)$ & $0(0)$ & $0(0)$ & $1(0.3)$ & $0(0)$ & $1(0.1)$ \\
\hline Streptococcus uberis & $0(0)$ & $0(0)$ & $0(0)$ & $0(0)$ & $3(0.9)$ & $3(0.4)$ \\
\hline Streptococcus agalactiae & $0(0)$ & $0(0)$ & $0(0)$ & $1(0.3)$ & $0(0)$ & $1(0.1)$ \\
\hline Staphylococcus aureus & $1(0.4)$ & $0(0)$ & $1(0.2)$ & $2(0.5)$ & $1(0.3)$ & $3(0.4)$ \\
\hline Other gram positive & $8(3.1)$ & $6(2.8)$ & $14(2.9)$ & $22(5.9)$ & $16(4.8)$ & $38(5.4)$ \\
\hline Total gram positive & $232(89.6)$ & $193(88.9)$ & $425(89.3)$ & $365(97.6)$ & $310(92.8)$ & $675(95.3)$ \\
\hline Pseudomonas spp. & $0(0)$ & $0(0)$ & $0(0)$ & $0(0)$ & $0(0)$ & $0(0)$ \\
\hline Serratia spp. & $1(0.4)$ & $3(1.4)$ & $4(0.8)$ & $2(0.5)$ & $1(0.3)$ & $3(0.4)$ \\
\hline Other gram negative & $7(2.7)$ & $7(3.2)$ & $14(2.9)$ & $2(0.5)$ & $11(3.3)$ & $13(1.8)$ \\
\hline Total gram negative & $27(10.4)$ & $24(11.1)$ & $51(10.7)$ & $9(2.4)$ & $24(7.2)$ & $33(4.7)$ \\
\hline Total isolates $\left[\right.$ no. $(\%)^{3}$ & $259(100)$ & $217(100)$ & $476(100)$ & $374(100)$ & $334(100)$ & $708(100)$ \\
\hline
\end{tabular}

${ }^{1}$ Dry-Clox (500 mg cloxacillin benzathine; Boehringer Ingelheim Vetmedica Inc., St Joseph, MO).

${ }^{2}$ Spectramast DC (500 mg ceftiofur hydrochloride; Zoetis, Florham Park, NJ).

${ }^{3}[\mathrm{n}(\%)]$ : $\mathrm{n}$ refers to number of events and the fraction (\%) refers to the proportion of all events. 


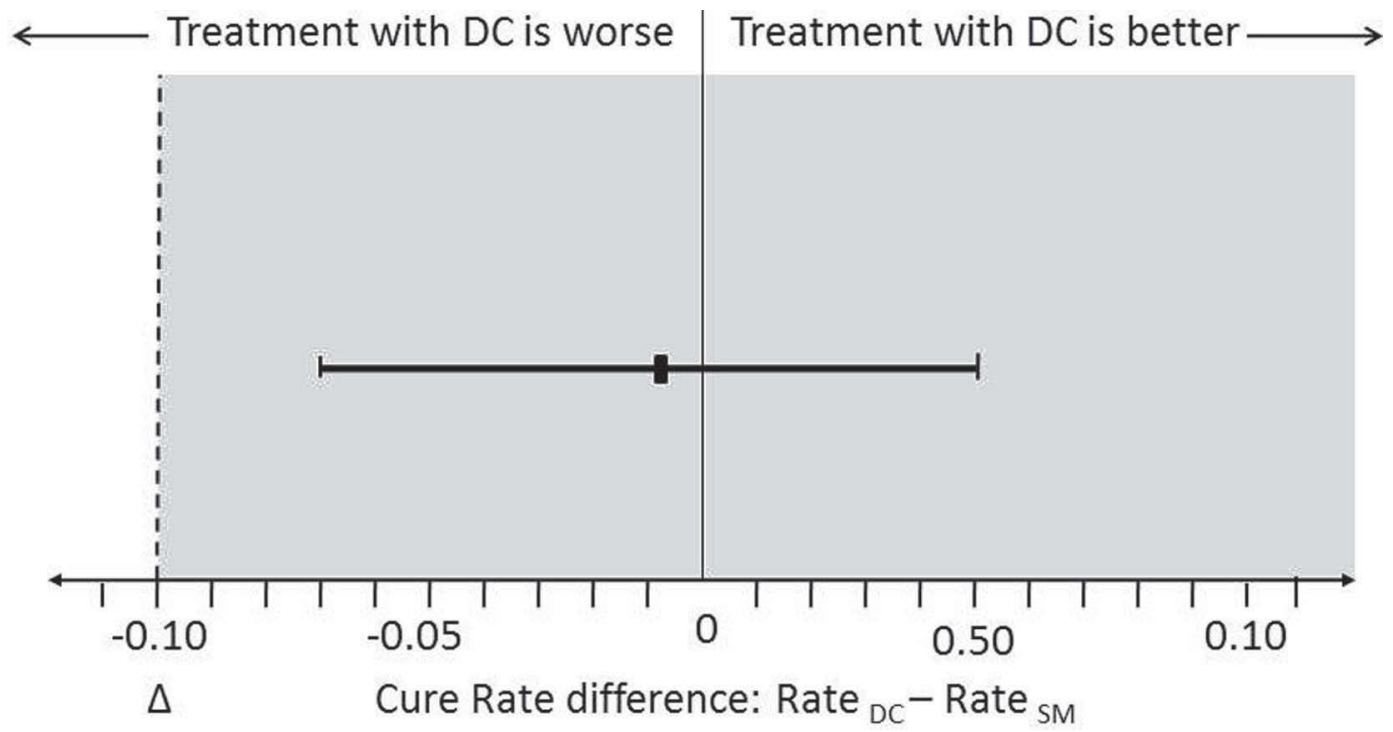

Figure 1. Difference in cure rate $[-0.0087(-0.0708,0.0534)]$ between Dry-Clox (DC; $84.8 \%$ cured) and Spectramast DC (SM; $85.7 \%$ cured) in the noninferiority trial, where the critical difference $(\Delta)$ is shown relative to the observed difference and associated $95 \%$ CI. The shaded area indicates zone of noninferiority.

0.0534). Because the lower bound of the CI for the rate difference (0.0708) was to the right of the critical value, $\Delta(0.10)$, it can be concluded that DC was noninferior relative to SM to effect a bacteriological cure during the dry period (Figure 1).

\section{Effect of Treatment on Risk for a Clinical Mastitis Event and on Risk for Removal from the Herd Between Dry Off and 100 DIM}

For quarter-level mastitis, the crude proportion of quarters experiencing a clinical mastitis event between dry off and 100 DIM was similar between the DC group $(2.99 \%, 48$ of 1,608$)$ and the SM group $(2.96 \%, 47$ of 1,588). The final Cox proportional hazards regression model found no difference between treatments as to the risk for a quarter-level clinical mastitis event between dry off and 100 DIM [hazard ratio SM $=0.95$ (0.64, 1.43), $P=0.82$; Table 8]. A significant effect of herd and a positive association between parity and quarter-level clinical mastitis risk were noted (Table 8). Although quarter samples were not made available for culture from all clinical mastitis events reported by farm staff (3/95 or $3.2 \%$ missing), culture results from those samples submitted show $53.3 \%$ with no bacterial growth, $33.7 \%$ with gram-positive growth, $12.0 \%$ with gram-negative growth, and $1.1 \%$ with other (yeast; Table 9).

For cow-level mastitis, the crude proportion of cows experiencing a clinical mastitis event between dry off and 100 DIM was similar between the DC group (16.96\%, 68 of 401) as compared with the SM group
(15.33\%, 61 of 398). The final Cox proportional hazards regression model also found no difference between treatments in risk for a cow-level clinical mastitis event between dry off and 100 DIM [hazard ratio ${ }_{S M}=0.89$ $(0.63,1.25), P=0.50$; Table 8$]$. A positive association between parity and cow-level clinical mastitis risk was observed. Whereas herd was not significant, it was forced into the model to control for clustering of cows within herd (Table 8).

The crude proportion of cows removed from the herd between dry off and 100 DIM was similar between the DC group $(10.7 \%, 43$ of 401) as compared with the SM group (10.3\%, 41 of 398). The final Cox proportional hazard regression model also found no difference between treatments in risk for removal from the herd during this period [hazard ratio $_{\mathrm{SM}}=0.97(0.63,1.50)$, $P=0.91$; Table 8]. A positive association between parity and removal risk was seen. Although herd was not significant, it was forced into the model to control for clustering of cows within herd (Table 8).

\section{Effect of Treatment on DHIA Test-Day Measures of LS, Components, and Milk Production in Early Lactation}

A total of 2,226 DHIA test-day records were recorded between calving and 100 DIM, including 757 first testday events $(\mathrm{DC}=377, \mathrm{SM}=380), 745$ second test-day events $(\mathrm{DC}=372, \mathrm{SM}=373)$, and 724 third test day events $(\mathrm{DC}=364, \mathrm{SM}=360)$. The mean $( \pm \mathrm{SD}) \mathrm{DIM}$ at first, second, and third DHIA test events was 14.9 $( \pm 8.6), 42.8( \pm 10.1)$, and $71.1( \pm 13.4)$, respectively. 
Table 8. Results of Cox proportional hazards regression estimating the effect of treatment on quarter- and cow-level clinical mastitis risk, and on risk for removal from the herd between dry off and 100 DIM, for cows infused with Dry-Clox ${ }^{1}$ or Spectramast DC ${ }^{2}$ at dry off

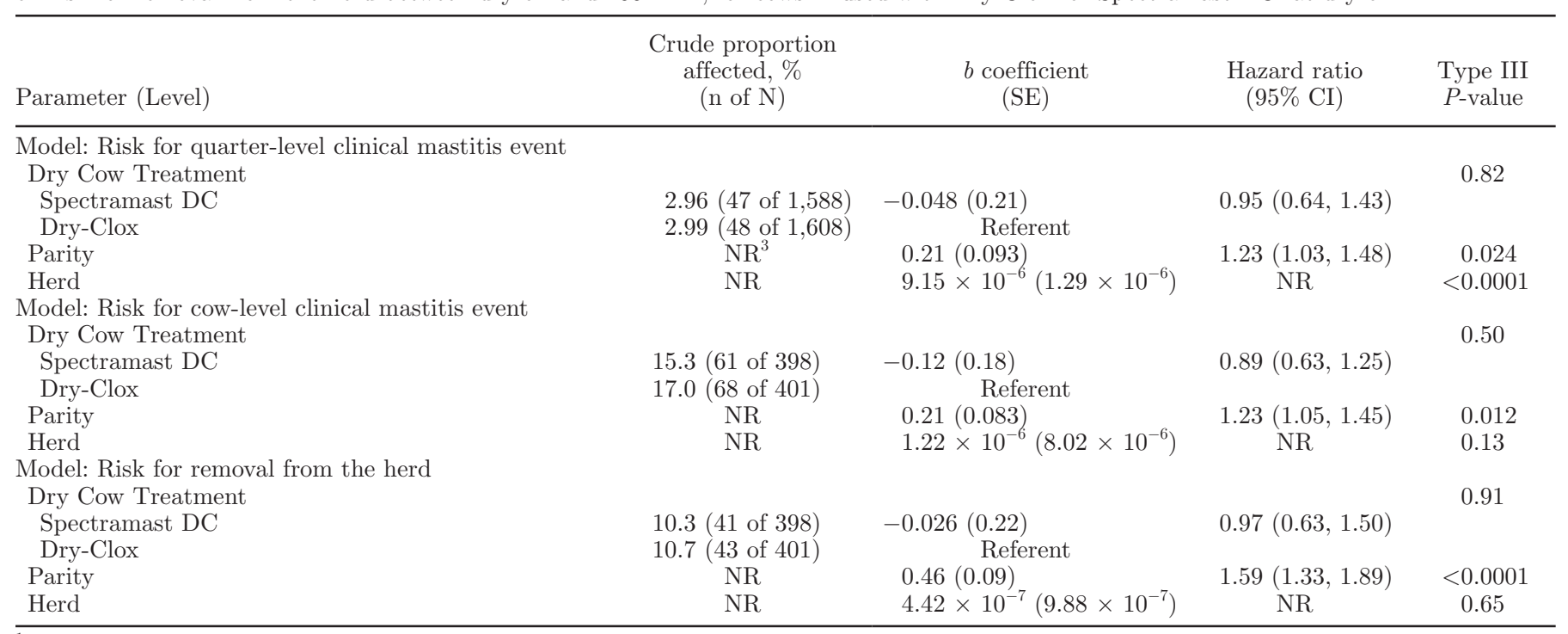

${ }^{1}$ Dry-Clox (500 mg cloxacillin benzathine; Boehringer Ingelheim Vetmedica, Inc., St Joseph, MO).

${ }^{2}$ Spectramast DC (500 mg ceftiofur hydrochloride; Zoetis, Florham Park, NJ).

${ }^{3} \mathrm{NR}=$ not reported.

After controlling for parity, DIM on test day, and herd as fixed effects, the final repeated measures linear regression models showed no difference between treatments as to the test-day $\mathrm{LS}(\mathrm{DC}=2.19, \mathrm{SM}=2.22, P$ $=0.68)$, butterfat test $(\mathrm{DC}=3.84 \%, \mathrm{SM}=3.86 \%, P$
$=0.48)$, protein test $(\mathrm{DC}=3.02 \%, \mathrm{SM}=3.02 \%, P=$ $0.83)$, and $305 \mathrm{ME}(\mathrm{DC}=11,817 \mathrm{~kg}, \mathrm{SM}=11,932 \mathrm{~kg}$, $P=0.11$; Table 10). However, because the latter model estimating the effect of treatment on $305 \mathrm{ME}(\mathrm{kg})$ found a significant treatment by herd interaction, the data

Table 9. Crude proportion and frequency of bacterial species from clinical mastitis events occurring between dry off and 100 DIM, for quarters infused with Dry-Clox ${ }^{1}$ or Spectramast DC ${ }^{2}$ at dry off

\begin{tabular}{|c|c|c|c|}
\hline \multirow[b]{2}{*}{ Item } & \multicolumn{3}{|c|}{ Clinical mastitis cases } \\
\hline & $\mathrm{DC}^{1}$ & $\mathrm{SM}^{2}$ & Total \\
\hline Total number of quarters at risk for clinical mastitis & 1,608 & 1,588 & 3,196 \\
\hline Quarters experiencing clinical mastitis $[\text { no. }(\%)]^{3}$ & $48(2.99)$ & $47(2.96)$ & $95(2.97)$ \\
\hline No culture result (sample not submitted) & 1 & 2 & 3 \\
\hline Known culture result (samples submitted for culture) & 47 & 45 & 92 \\
\hline No bacterial growth ${ }^{4}$ & $23(48.9)$ & $26(57.8)$ & $49(53.3)$ \\
\hline \multicolumn{4}{|l|}{ Gram positive $[\text { no. }(\%)]^{4}$} \\
\hline Aerococcus spp. & $0(0)$ & $4(8.9)$ & $4(4.3)$ \\
\hline Bacillus spp. & $2(4.3)$ & $1(2.2)$ & $3(3.3)$ \\
\hline CNS & $6(12.8)$ & $5(11.1)$ & $11(12.0)$ \\
\hline Corynebacterium spp. & $1(2.1)$ & $0(0)$ & $1(1.1)$ \\
\hline Enterococcus spp. & $2(4.3)$ & $3(6.7)$ & $5(5.4)$ \\
\hline Other gram positive & $3(6.4)$ & $4(8.9)$ & $7(7.6)$ \\
\hline Total gram positive & $14(29.9)$ & $17(37.8)$ & $31(33.7)$ \\
\hline \multicolumn{4}{|l|}{ Gram negative $[\text { no. }(\%)]^{4}$} \\
\hline Escherichia coli & $7(14.9)$ & $1(2.2)$ & $8(8.7)$ \\
\hline Klebsiella spp. & $1(2.1)$ & $0(0)$ & $1(1.1)$ \\
\hline Other gram negative & $1(2.1)$ & $1(2.2)$ & $2(2.2)$ \\
\hline Total gram negative & $9(19.1)$ & $2(4.4)$ & $11(12.0)$ \\
\hline Other, ${ }^{4}$ yeast & $1(2.1)$ & $0(0)$ & $1(1.1)$ \\
\hline \multirow{2}{*}{\multicolumn{4}{|c|}{${ }^{1}$ Dry-Clox (500 mg cloxacillin benzathine; Boehringer Ingelheim Vetmedica, Inc., St Joseph, MO). }} \\
\hline & & & \\
\hline \multicolumn{4}{|c|}{${ }^{3}[\mathrm{n}(\%)]: \mathrm{n}$ refers to number of events and the fraction $(\%)$ refers to the proportion of all events. } \\
\hline
\end{tabular}


Table 10. Results of final main effects linear regression models describing the effect of treatment on DHIA test day linear score, milk components, and milk yield between calving and 100 DIM, for cows infused with Dry-Clox ${ }^{1}$ or Spectramast DC ${ }^{2}$ at dry off ${ }^{3}$

\begin{tabular}{llccc}
\hline Outcome variable & Treatment group & $\begin{array}{c}\text { Adjusted mean } \\
(\mathrm{SE})\end{array}$ & $\begin{array}{c}b \text { coefficient } \\
(\mathrm{SE})\end{array}$ & $\begin{array}{c}\text { Type III } \\
P \text {-value }\end{array}$ \\
\hline SCC linear score & Dry-Clox & $2.19(0.06)$ & $-0.03(0.08)$ & 0.68 \\
& Spectramast DC & $2.22(0.06)$ & Referent & \\
Butter fat $(\%)$ & Dry-Clox & $3.84(0.02)$ & $-0.02(0.03)$ & 0.48 \\
& Spectramast DC & $3.86(0.02)$ & Referent & \\
Protein $(\%)$ & Dry-Clox & $3.02(0.01)$ & $-0.003(0.014)$ & 0.83 \\
& Spectramast DC & $3.02(0.01)$ & Referent & \multirow{2}{*}{0.11} \\
$305 \mathrm{ME}^{4}(\mathrm{~kg})$ & Dry-Clox & $11,817(50.8)$ & $-115.5(71.8)$ & \\
& Spectramast DC & $11,932(50.8)$ & Referent & \\
\hline
\end{tabular}

${ }^{1}$ Dry-Clox (500 mg cloxacillin benzathine; Boehringer Ingelheim Vetmedica, Inc., St Joseph, MO).

${ }^{2}$ Spectramast DC (500 mg ceftiofur hydrochloride; Zoetis, Florham Park, NJ).

${ }^{3}$ All models adjusted for DIM on test day, parity, and herd as fixed effects, plus repeated measures by test day number $(1,2,3)$.

${ }^{4} 305 \mathrm{ME}=305$-d mature-equivalent milk yield

was stratified by herd and reanalyzed. Stratified analysis showed a positive effect of treatment with DC in herd $4(\mathrm{DC}=12,729 \mathrm{~kg}, \mathrm{SM}=12,383 \mathrm{~kg}, P=0.014)$, a negative effect of treatment with $\mathrm{DC}$ in herd $3(\mathrm{DC}=$ $11,843 \mathrm{~kg}, \mathrm{SM}=12,520 \mathrm{~kg}, P<0.0001)$, and no effect of treatment with $\mathrm{DC}$ in herd $1(\mathrm{DC}=9,952 \mathrm{~kg}$. $\mathrm{SM}=$ $10,091 \mathrm{~kg}, P=0.21)$ and herd $2(\mathrm{DC}=12,707 \mathrm{~kg}, \mathrm{SM}$ $=12,763 \mathrm{~kg}, P=0.69$; models not shown).

\section{DISCUSSION}

Ours is the first multiherd randomized clinical trial conducted in North American dairy herds designed specifically to compare efficacy between DC (cloxacillin benzathine) and SM (ceftiofur hydrochloride) in terms of udder health and cow performance during the first $100 \mathrm{~d}$ of lactation. Strengths of the current study include a large sample size (adequate power), successful randomization of cows to treatment (i.e., similar baseline characteristics), and the fact that it was conducted in multiple commercial herds using different housing systems (freestall, bedded pack) and different bedding materials (recycled sand, biosolids, straw) during the dry period. An additional strength is the longer-term follow-up of cows and quarters beyond the immediate postpartum period. When conducting treatment efficacy studies such as this one, it is important not only describe the effect of treatment on bacteriological findings in the immediate postpartum period, but also on other longer-term and more clinically and economically relevant outcomes such as SCC, milk production, clinical mastitis risk, and culling risk.

One possible limitation that could affect generalizability of results is that, whereas study herds had similar average milk production $(40.3 \mathrm{~kg} / \mathrm{cow}$ per day) and SCC $(172,500$ cells $/ \mathrm{mL})$ as compared with other
Midwest herds with more than 1,000 cows $(40.5 \mathrm{~kg} /$ cow per day, 179,000 cells $/ \mathrm{mL}$ ), study herds were larger (1,663 lactating cows), produced more milk, and had lower average SCC as compared with Midwest Holstein herds of all sizes (185 lactating cows, $33.2 \mathrm{~kg} /$ cow per day, 213,000 cells/mL; AgSource Cooperative Services, Vernon, WI). Study herds were also larger than average for all US dairy herds (167 lactating cows; USDA-NAHMS, 2010). Finally, all study herds used an internal teat sealant at dry off (Orbeseal, Zoetis) and a coliform mastitis vaccine (Enviracor J-5, Zoetis). The 2007 NAHMS study reported that approximately $30 \%$ of all operations, and approximately $49 \%$ of larger operations with $\geq 500$ cows, routinely use an internal teat sealant (USDA-NAHMS, 2008). Similarly, approximately $38 \%$ of all operations reported vaccinating for coliform mastitis (USDA-NAHMS, 2010). As such, although results of that study are generalizable to herds similar to those used in the current study, future studies could investigate if findings are similar in smaller herds or herds not routinely using internal teat sealants at dry off.

Another point for discussion is whether or not it was a limitation in the study design that IMI status after calving was assessed using only a single sample collected between 0 to 10 DIM. The decision to use a single sample was based upon our belief that collecting a single sample would not negatively affect the validity of study findings. A previous study evaluating the relative sensitivity and specificity of diagnosing IMI using a single sample (vs. multiple samples), reported that triplicate samples collected over consecutive days provided only a modest gain in specificity and little or no gain in sensitivity as compared with a single sample (Dohoo et al., 2011b). As such, we do not consider the use of a single sample for diagnosing IMI after calv- 
ing to be a limitation. Furthermore, our finding of no difference in IMI rate at calving is supported by the longer-term observations associated with udder health in that no effect of treatment on clinical mastitis risk or on SCC LS measures were observed over all DHIA tests occurring between 0 and 100 DIM. It makes biological sense that if IMI rates at calving did not differ by treatment group, then clinical mastitis risk and early lactation SCC LS measures should also not differ by treatment group, as it is well understood that SCC is elevated as an inflammatory response to infection, and that quarters infected at calving will have increased risk for clinical mastitis and increased SCC measures in early lactation (Barkema et al., 1999; Schukken et al., 2003).

When considering the short-term quarter-level outcomes, no difference between groups was noted in prevalence of IMI at dry off, and no difference was noted in efficacy as measured by cure risk or risk for new IMI between dry off and 0 to 10 DIM. As such, it was not surprising that no treatment difference was observed in the risk for presence of IMI at 0 to 10 DIM. Overall, the crude prevalence of IMI at dry off $(34.7 \%)$ and calving (23.0\%), the incidence of cure $(85.1 \%)$, and the incidence of NIMI (18.5\%) for the current study were similar with results of other North American dry cow mastitis studies. Previous studies have reported the prevalence of IMI to range between 12.8 and $32 \%$ at dry off and between 6.9 and $22.8 \%$ postcalving, respectively (Godden et al., 2003; Pantoja et al., 2009; Arruda et al., 2013a). Also, previous studies have reported NIMI incidence and cure rates during the dry period to vary between 6 and 36\% (NIMI) and between 61.8 and $88.9 \%$ (cures), respectively (Godden et al., 2003; Cook et al., 2005; Hallberg et al., 2006; Pantoja et al., 2009; Gundelach et al., 2011; Arruda et al., 2013a). Regarding the relatively low cure rates for ceftiofur hydrochloride (61.8\%) reported by Hallberg et al., (2006), it should be noted that their study only enrolled cows with a high SCC, which may have represented more chronic infections that were less likely to cure.

That the current study found no difference in efficacy between DC and SM is consistent with the fact that both DCT products are labeled to be effective against one or more gram-positive organisms, and that the majority of IMI detected in the current study were caused by gram-positive organisms. Neither of the 2 products evaluated are labeled against gram-negative organisms, even though it is recognized that they will have different degrees of gram-negative activity in in vitro tests, with SM expected to have more activity against gram-negative organisms than DC (Salmon et al., 1996; Oliver and Murinda, 2012). These findings are in agreement with previous dry cow studies that report varying but relatively low proportions of IMI caused by gram-negative pathogens at dry off, with estimates ranging between 0.25 and $22 \%$ (Godden et al., 2003; Hallberg et al., 2006; Pantoja et al., 2009; Arruda et al., 2013a). In the current study, only $4.3 \%$ of all subclinical IMI present at dry off (and therefore at risk for a cure) were caused by a gram-negative organism. Similarly, only $10.7 \%$ of NIMI acquired during the dry period were caused by a gram-negative organism. It is possible that SM might prove to be more efficacious than DC in herds with a greater proportion of dry cow mastitis infections caused by gram-negative organisms. However, this hypothesis requires testing in a different set of herds with a greater proportion of infections present at dry off or a greater proportion of NIMI acquired during the dry period caused by gram-negative organisms.

The current study reported very few infections at dry off caused by the contagious pathogens, Staph. aureus ( $0.4 \%$ of IMI) and Strep. agalactiae (0.1\% of IMI). The low number of Staph. aureus and Strep. agalactiae common to all study herds is consistent with other dry cow studies in the United States (Arruda et al., 2013a) and very likely reflects good overall mastitis control programs. This includes the implementation of the FivePoint Program, a program developed at the National Institute for Research in Dairying in England that was adopted by progressive herds to control and prevent IMI caused by contagious pathogens.

Given that no difference was seen between treatments as to the prevalence of IMI at 0 to 10 DIM, it was not surprising that we also found no difference between treatments in the early lactation measures of udder health and cow performance, including quarter- and cow-level risk for a clinical mastitis event between dry off and 100 DIM, cow-level risk for removal from the herd between dry off and culling, and DHIA test-day results between calving and 100 DIM, including LS, butterfat test, protein test, and 305ME milk production. The overall crude incidence of clinical mastitis occurring between dry off and 100 DIM at the quarter- $(3.0 \%)$ and cow-level $(16.1 \%)$ was very similar to previous dry cow mastitis studies which have reported early lactation clinical mastitis incidence rates ranging between 3 and $6 \%$ (quarter-level) or between 10.1 and $14.2 \%$ (cow-level; Godden et al., 2003; Gundelach et al., 2011; Pinedo et al., 2012; Arruda et al., 2013a). The overall crude removal rate between enrollment and 100 DIM for the current study (10.5\%) was consistent with Arruda et al. (2013b), which reported a 9\% removal rate from calving to 100 DIM. In the current study, most of these events occurred after calving; very few quarterlevel clinical mastitis cases $(5.3 \%$ or 5 of 95 quarters affected), cow-level clinical mastitis cases $(2.3 \%$, or 3 of 
129 cows affected), and cow removal events $(8.3 \%$, or 7 of 84 cows removed) occurred in the period between dry off and calving. Although no treatment difference was observed in DHIA test d 305ME milk yield, we cannot explain why we found a treatment by herd interaction, nor specifically why a positive effect of treatment was seen with DC in herd 4, a negative effect in herd 3, and no effect in herds 1 and 2.

\section{CONCLUSIONS}

Results from this randomized clinical trial demonstrate that, in herds using blanket Orbeseal infusion at dry off and a coliform mastitis vaccination program, and where gram-positive infections represented $>90 \%$ of subclinical IMI present at dry-off and after calving, there was no difference in efficacy between DC and SM regarding risk for presence of IMI at 0 to 10 DIM, risk for experiencing a cure during the dry period, risk for developing a NIMI between dry off and 0 to 10 DIM, and risk for experiencing a clinical mastitis event at either the quarter- or cow-level between dry off and 100 DIM. Similarly, no difference was noted between treatments for risk of removal from the herd between dry off and 100 DIM, or for DHIA test-day measures during the first 100 DIM including LS, milk butterfat and protein percentage, and 305ME milk production.

\section{ACKNOWLEDGMENTS}

Financial support for this study was provided by Boehringer Ingelheim Vetmedica Inc. (St. Joseph, MO). The authors thank the farm owners and staff for their participation, as well as the Waupun Veterinary Service Milk Quality Laboratory (Waupun, WI).

\section{REFERENCES}

Arruda, A. G., S. Godden, P. Rapnicki, P. Gorden, L. Timms, S. S. Aly, T. Lehenbauer, and J. Champagne. 2013a. Randomized non-inferiority clinical trial evaluating three commercial dry cow mastitis preparations: I. Quarter-level outcomes. J. Dairy Sci. 96:4419-4435.

Arruda, A. G., S. Godden, P. Rapnicki, P. Gorden, L. Timms, S. S. Aly, T. Lehenbauer, and J. Champagne. 2013b. Randomized non-inferiority clinical trial evaluating three commercial dry cow mastitis preparations: II. Cow health and performance in early lactation. J. Dairy Sci. 96:6390-6399.

Barkema, H. W., H. A. Deluyker, Y. H. Schukken, and T. J. G. M. Lam. 1999. Quarter-milk somatic cell count at calving and at the first six milkings after calving. PVM 38:1-9.

Bradley, A. J., and M. J. Green. 2000. A study of the incidence and significance of intramammary enterobacterial infections acquired during the dry period. J. Dairy Sci. 83:1957-1965.

Cook, N. B., D. Pionek, and P. Sharp. 2005. An assessment of the benefits of Orbeseal when used in combination with dry cow therapy in three commercial dairy herds. Bovine Pract. 39:83-94.
Dohoo, I., S. Anderson, R. Dingwell, K. Hand, D. Kelton, K. Leslie, Y. Schukken, and S. Godden. 2011b. Diagnosing intramammary infections: Comparison of multiple versus single quarter milk samples for the identification of intramammary infections in lactating dairy cows. J. Dairy Sci. 94:5515-5522.

Dohoo, I. R., J. Smith, S. Andersen, D. F. Kelton, S. Godden, and Mastitis Research Workers' Conference. 2011a. Diagnosing intramammary infections: Evaluation of definitions based on a single milk sample. J. Dairy Sci. 94:250-261.

Erskine, R. J. 2001. Enhancing immunity during the dry period: Pitfalls and opportunities. Pages 95-101 in Natl. Mastitis Counc. Mtg. Proc. Reno, NV. Natl. Mastitis Counc. Inc., Madison, WI.

Godden, S., P. Rapnicki, S. Stewart, J. Fetrow, A. Johnson, R. Bey, and R. Farnsworth. 2003. Effectiveness of an internal teat seal in the prevention of new intramammary infections during the dry and early-lactation periods in dairy cows when used with a dry cow intramammary antibiotic. J. Dairy Sci. 86:3899-3911.

Green, M. J., L. E. Green, G. F. Medley, Y. H. Schukken, and A. J. Bradley. 2002. Influence of dry period bacterial intramammary infection on clinical mastitis in dairy cows. J. Dairy Sci. 85:25892599 .

Gundelach, Y., E. Kalscheuer, H. Hamann, and M. Hoedemaker. 2011. Risk factors associated with bacteriological cure, new infection, and incidence of clinical mastitis after dry cow therapy with three different antibiotics. J. Vet. Sci. 12:227-233.

Hallberg, J. W., M. Wachowski, W. M. Moseley, K. J. Dame, J. Meyer, and S. L. Wood. 2006. Efficacy of intramammary infusion of ceftiofur hydrochloride at drying off for treatment and prevention of bovine mastitis during the nonlactating period. Vet. Ther. 7:35-42.

National Milk Producers Federation. 2014. Milk and Dairy Beef Drug Residue Prevention. National Dairy Farm Program. Page 29. Accessed June 20, 2015. http://www.nationaldairyfarm.com/sites/ default/files/2014\%20Residue\%20Manual_WEB.pdf.

NMC. 1999. Laboratory Handbook on Bovine Mastitis. National Mastitis Council, Madison, WI.

Oliver, S. P., and S. E. Murinda. 2012. Antimicrobial resistance of mastitis pathogens. Vet. Clin. North Am. Food Anim. Pract. $28: 165-185$.

Pantoja, J. C., C. Hulland, and P. L. Ruegg. 2009. Dynamics of somatic cell counts and intramammary infections across the dry period. Prev. Vet. Med. 90:43-54.

Piaggio, G., D. R. Elbourne, D. G. Altman, S. J. Pocock, and S. J. W. Evans. 2006. Reporting of noninferiority and equivalence randomized trials - An extension of the CONSORT statement. JAMA 295:1152-1160.

Pinedo, P. J., C. Fleming, and C. A. Risco. 2012. Events occurring during the previous lactation, the dry period, and the peripartum as risk factors for early lactation mastitis in cows receiving 2 different intramammary dry cow therapies. J. Dairy Sci. 95:7015-7026.

Salmon, S. A., J. L. Watts, and R. J. Yancey Jr.. 1996. In vitro activity of ceftiofur and its primary metabolite, desfuroylceftiofur, against organisms of veterinary importance. J. Vet. Diagn. Invest. 8:332-336.

Schukken, Y. H., D. J. Wilson, F. Welcome, L. Garrison-Tikofsky, and R. N. Gonzalez. 2003. Monitoring udder health and milk quality using somatic cell counts. Vet. Res. 34:579-596.

Smith, K. L., D. A. Todhunter, and P. S. Schoenberger. 1985. Environmental pathogens and intramammary infection during the dry period. J. Dairy Sci. 68:402-417.

Todhunter, D. A., K. L. Smith, and J. S. Hogan. 1995. Environmental streptococcal intramammary infections of the bovine mammary gland. J. Dairy Sci. 78:2366-2374.

USDA-NAHMS. 2008. Dairy 2007. Part III: Reference of Dairy Cattle Health and Management Practices in the United States, 2007. Accessed Jun. 21, 2015. http://www.aphis.usda.gov/animal_health/ nahms/dairy/downloads/dairy07/Dairy07_dr_PartIII_rev.pdf.

USDA-NAHMS. 2010. Dairy 2007. Biosecurity practices on U.S. dairy operations, 1991-2007. Accessed Jun. 21, 2015. http://www. aphis.usda.gov/animal_health/nahms/dairy/downloads/dairy07/ Dairy07_ir_Biosecurity.pdf 